\title{
Investigation of Metabolite Profile of YM758, a Novel If Channel Inhibitor
}

\author{
Naoyuki Nakada ${ }^{1}$
}

Published online: 30 March 2016

(C) The Author(s) 2016. This article is published with open access at Springerlink.com

\begin{abstract}
Background YM758 monophosphate is a novel If channel inhibitor that has an inhibitory action for If current and shows a strong and specific activity, selectively lowering the heart rate and decreasing oxygen consumption by heart muscle.

Objectives The objectives of the current study were to investigate the in vivo metabolic profiles of YM758 in mice, rats, rabbits, dogs, and monkeys and to elucidate the structures of YM758 metabolites.

Methods Biological samples were analyzed by liquid chromatography hyphenated with a radiometric detection system and liquid chromatography coupled with a mass spectrometer to clarify their metabolic patterns. To elucidate their structures, metabolites were isolated and analyzed by mass spectrometry and nuclear magnetic resonance spectroscopy.

Results Our results from in vivo metabolic profiling in humans and animals indicated there is no significant species difference in the metabolism of YM758, and the metabolic pathways of YM758 are considered to be oxidation, hydration, and demethylation followed by sulfate or glucuronide conjugation.
\end{abstract}

Naoyuki Nakada

naoyuki.nakada@astellas.com

1 Analysis and Pharmacokinetics Research Laboratories, Drug Discovery Research, Astellas Pharma Inc., Miyukigaoka 21, Tsukuba, Ibaraki 305-8585, Japan

\section{Key Points}

We conducted quantitative metabolic profiling in rats using ${ }^{14} \mathrm{C}$-YM758, and metabolism was considered to be diverse.

The results of metabolic profiling in mice, rats, rabbits, dogs, and monkeys suggest there are no human-specific circulating metabolites.

The YM758 metabolites were elucidated by mass spectrometry and nuclear magnetic resonance, and the main metabolic pathways of YM758 in rats are thought to be (1) hydroxylation and (2) oxidation followed by hydration, (3) amide hydrolysis, and (4) $O$-demethylation followed by sulfate or glucuronide conjugation.

\section{Introduction}

YM758 monophosphate, $(-)-N-\{2-[(R)-3-(6,7-d i m e t h o x y-$ 1,2,3,4-tetrahydroisoquinoline-2-carbonyl)piperidino]ethyl)-4-fluorobenzamide monophosphate (Fig. 1), has an inhibitory action for the If current and shows a strong and specific activity, selectively lowering the heart rate and decreasing the oxygen consumption of heart muscle. As such, it is useful as a preventive and/or treating agent for diseases of the circulatory system, such as ischemic heart diseases (e.g., angina pectoris and myocardial infarction), congestive heart failure, and arrhythmia, etc. [1]. In clinical trials, it has been reported that the If channel inhibitors 
<smiles>COc1cc2c(cc1OC)CN(C(=O)[C@H]1CCCN(CCNC(=O)c3ccc(F)cc3)C1)CC2</smiles>

YM758 monophosphate<smiles>COc1cc2c(cc1OC)CN(C(=O)[C@H]1CCC(=O)NC1)CC2</smiles>

YM-385459 (R3)

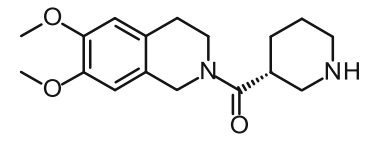

YM-252124 (R4)<smiles>O=C(O)CNC(=O)c1ccc(F)cc1</smiles>

YM-385461 (R8)<smiles>O=C(NCCN1CCC[C@H](C(=O)O)C1)c1ccc(F)cc1</smiles>

YM-234903 (R9)

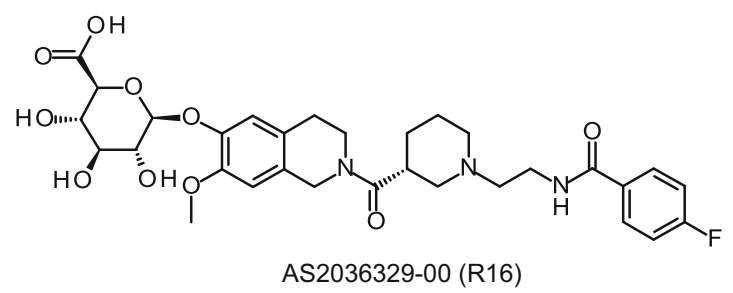

Fig. 1 Chemical structures of YM758 monophosphate with tentative numbering. (Asterisk ${ }^{14} \mathrm{C}$ labeled position), YM-385459 (R3), YM252124 (R4), YM-385461 (R8), YM-234903 (R9), and AS203632900 (R16)

zatebradine and ivabradine reduce the heart rate without concomitant negative inotropic or hypotensive effects [25]. The pharmacokinetic profiles of YM758 in humans and test animals have been investigated elsewhere [6-8]; however, the inter-species differences in its metabolic profile and the structures of the metabolites have not yet been described. It is important to investigate the metabolite profile in experimental animals to understand the difference in pharmacologic and toxicological effects of the drug. The objectives of the current study were to investigate the in vivo metabolic profiles of YM758 in mice, rats, rabbits, dogs, and monkeys and elucidate the structures of the metabolites of YM758.

\section{Materials and Methods}

\subsection{Chemicals}

YM758 monophosphate, YM-385459 (R3), YM-252124 (R4), YM-385461 (R8), YM-234903 (R9), and AS2036329-00 (R16) (Fig. 1) were synthesized at Astellas Pharma Inc. (Ibaraki, Japan). ${ }^{14} \mathrm{C}-\mathrm{YM} 758$ monophosphate (98\% radiochemical purity, $3.14 \mathrm{MBq} / \mathrm{mg}$ ), was synthesized at Sekisui Medical (Ibaraki, Japan). All commercially available regents used in this study were of the highest quality and analytical grade. We used acetonitrile (Kanto Chemical, Tokyo, Japan) and ammonium acetate (NacalaiTesque, Kyoto, Japan) to prepare the high-performance liquid chromatography (HPLC) mobile phase, and pico-fluor 40 (PerkinElmer; Wellesley, MA, USA) for scintillation counting.

\subsection{Equipment}

We used an LC-10A HPLC system (Shimadzu, Kyoto, Japan) with a fraction collector SF-2120 (Advantec, Tokyo, Japan) to isolate metabolites and Q-TOF Ultima (Waters, Milford, MA, USA) and TSQ7000 (Thermo Fisher Scientific, Waltham, MA, USA) for mass spectrometry (MS) analysis. JNM-ALPHA500 (JEOL, Tokyo, Japan) and INOVA600 (Varian, Palo Alto, CA, USA) were used for nuclear magnetic resonance (NMR) spectroscopy analysis. An LC-VP HPLC system (Shimadzu) with a radiometric detector FLO-ONE/A525AX (PerkinElmer) was used for liquid chromatography (LC), coupled with a radiometric detection system (LC-RAD), to investigate in vivo metabolic profiles in rat urine and bile. A fraction collector DC1500 (EYELA, Tokyo Japan) and a liquid scintillation counter 2700TR (PerkinElmer) were also used for metabolic profiling in rat plasma. Agilent 1100 HPLC (Agilent Technologies, Palo Alto, CA, USA), a radiometric detector FLO-ONE/625TR (PerkinElmer), and an LCQ Deca XP Plus (Thermo Fisher Scientific) were used for LC coupled with an MS system (LC-RAD/MS) to confirm whether each radioactivity peak was derived from several metabolites in the metabolic profiling in rat urine, bile, and plasma. Agilent 1100 and 3133 (Shiseido, Tokyo, Japan) HPLC coupled with TSQ Quantum Discovery Max (Thermo Fisher Scientific) were used for selected reaction monitoring analysis (SRM) to identify the in vivo metabolites with their authentic standards in mouse, rat, rabbit, dog, and monkey plasma collected after single doses of non-labeled YM758. 


\subsection{Animals}

This study was conducted in male $\mathrm{B} 6 \mathrm{C} 3 \mathrm{~F} 1$ mice and Fischer 344 (F344) rats (both 9 weeks old) supplied by Charles River Japan (Kanagawa, Japan), 18-week-old female New Zealand white (NZW) rabbits supplied by Kitayama Labes (Nagano, Japan), 11-month-old male Beagle dogs supplied by the Institute for Animal Reproduction (Ibaraki, Japan), and $\geq 3$-year-old male cynomolgus monkeys supplied by KEARI Co., Ltd. (Osaka, Japan). Mice, rats, and rabbits were used after acclimatization for at least 1 week, and dogs and monkeys were used after acclimatization for 16 and 22 days, respectively. The body weights of mice, rats, rabbits, dogs, and monkeys were $20.2-24.8 \mathrm{~g}, 168.2-186.9 \mathrm{~g}, 2.85-3.17 \mathrm{~kg}, 9.10-10.60 \mathrm{~kg}$, and $3.24-3.36 \mathrm{~kg}$, respectively. The animal experiments were approved by an ethics committee and conducted in accordance with the institutional guidelines of the test facilities. The doses of YM758 were set according to the results of toxicity studies to avoid toxicity.

\subsection{Metabolic Profiling in Rat Urine, Bile, and Plasma}

Male F344 rat urine and bile samples collected for 0-6 and 6-24 h and plasma samples collected at 0.5 and $1 \mathrm{~h}$ (plasma and bile, $n=3$ each; urine, $n=4$ ) after a single oral administration of ${ }^{14} \mathrm{C}$-labeled YM758 $\left({ }^{14} \mathrm{C}\right.$-YM758) at a dose of $1 \mathrm{mg}$ free base/kg were obtained in a previous study [7]. The urine and bile samples were pooled according to the time interval in which they were collected, and the pooled samples were used for analysis. The plasma samples were pooled according to the time point at which they were collected, and the pooled plasma samples were then deproteinized using acetonitrile and centrifuged. The supernatant was concentrated under a stream of nitrogen gas, and the remaining aqueous solution was centrifuged. The supernatant was then used for analysis.

The analytical samples and isolated metabolites were subjected to LC-RAD/MS, and the retention times (RTs) of radioactivity peaks in the biological samples and the ultraviolet (UV) peaks of the isolated metabolites were compared. MS analysis confirmed whether a radioactivity peak contained several metabolites.

\subsection{Identification of Metabolites of YM758 in Mouse, Rat, Rabbit, Dog, and Monkey Plasma}

To identify the metabolites detected in humans [8], YM758 monophosphate was given to mice, rats, rabbits, and dogs at the single oral doses of $250,250,10$, and $10 \mathrm{mg} / \mathrm{kg}$, respectively, and was given to monkeys at a single intravenous dose of $3 \mathrm{mg} / \mathrm{kg}$. Mouse, rat, rabbit, and dog blood samples were obtained at 1, 2, 6, and $24 \mathrm{~h}$ after administration using a heparinized syringe, and monkey blood samples were obtained at $0.5,1,2$, and $4 \mathrm{~h}$ after administration using a heparinized syringe. The blood samples were centrifuged and plasma samples were obtained. To confirm the presence of unchanged YM758 and its metabolites, $1.5-\mathrm{ml}$ portions of plasma samples in each animal were diluted with $1.5 \mathrm{ml}$ of $1 \%$ acetic acid and applied to a solid-phase extraction cartridge, Oasis HLB (Waters). The extracts were analyzed using a LC-MS, and the metabolites were detected by SRM. The metabolites, R3, R4, R8, and R16, were identified using the synthetic authentic standards, YM-385459, YM-252124, YM385461, and AS2036329-00.

\subsection{Isolation and Structure Elucidation of Metabolites}

YM758 monophosphate was suspended in $0.5 \%$ methylcellulose to prepare $40 \mathrm{mg}$ free base $/ \mathrm{ml}$ of dosing suspension. This suspension was given to rats at an oral dose of $200 \mathrm{mg}$ free base $/ \mathrm{kg}$, and urine samples were collected for $24 \mathrm{~h}$ post-dose. The dosing suspension was also given to bile duct-cannulated rats at the same dosage, and bile samples were collected for $24 \mathrm{~h}$ post-dose.

An aliquot volume (about $202 \mathrm{ml}$ ) of the pooled rat urine was applied to an Oasis HLB (35 cc/6 g) cartridge. The cartridge was then washed with $50 \mathrm{ml}$ of water and eluted with $60 \mathrm{ml}$ of acetonitrile. The eluted fraction was then subjected to preparative HPLC, and six metabolites, R1 (3.23 mg), R2 (0.51 mg), R3 (6.77 mg), R4 (31.44 mg), R8 (1.04 mg), and R9 (1.04 mg), were isolated.

An aliquot volume (about $125 \mathrm{ml}$ ) of the pooled rat bile was lyophilized, the residue was subjected to preparative HPLC, and 11 metabolites, R10 (5.85 mg), R11 (0.99 mg), R12 (0.57 mg), R13 (2.67 mg), R14 (1.00 mg), R16 (43.37 mg), R17 (4.87 mg), R18 (0.05 mg), R19 (1.49 mg), R20 (4.14 mg), and R21 (0.51 mg), were isolated.

The isolated metabolites and YM758 monophosphate were subjected to MS and NMR analysis. Tetramethylsilane was used as the reference for NMR chemical shifts. NMR measurement of R19 was conducted using dimethylsulfoxide- $d_{6}$, and methanol- $d_{4}$ was used for the other metabolites and YM758. To elucidate the structure of R9, the synthetic sample, YM-234903, which is estimated to be the same structure, was used and their NMR spectra compared. Two-dimensional NMR analysis was performed to obtain further information such as elucidation of the conjugating position. A high-resolution MS, Q-TOF 
Ultima, was used to determine the molecular formula of R3 and R8.

\subsection{Analytical HPLC Conditions}

Common HPLC conditions were used for LC-RAD/MS and LC-RAD. HPLC analysis was performed using an Inertsil ODS-3 column $(5 \mu \mathrm{m}, 250 \mathrm{~mm} \times 4.6 \mathrm{~mm}$ i.d., GL Sciences, Tokyo, Japan) operating at $40{ }^{\circ} \mathrm{C}$. A flow rate of $1 \mathrm{ml} / \mathrm{min}$ was used with a gradient elution using solvent $\mathrm{A}$ (10 mmol/1 ammonium acetate/acetonitrile = 19/1) and B $(10 \mathrm{mmol} / \mathrm{l}$ ammonium acetate/acetonitrile $=1 / 19)$. The proportion of solvent $\mathrm{B}$ was increased linearly from 0 to $20 \%$ over $30 \mathrm{~min}$, and then increased linearly up to $40 \%$ between 30 and $45 \mathrm{~min}$, and then increased linearly up to $100 \%$ between 45 and $60 \mathrm{~min}$, and held at $100 \%$ between 60 and $65 \mathrm{~min}$. Except for the analytes from rat plasma samples, the radioactivity of ${ }^{14} \mathrm{C}$ was monitored using an online radiometric detector. Radiometric analysis for rat plasma samples required HPLC fractionation, and the radioactivity of ${ }^{14} \mathrm{C}$ was detected using a liquid scintillation counter because of the low level of radioactivity. The fractionation was performed using a fraction collector to separate into 120 eluate fractions (30-s interval).

\section{Results}

\subsection{Metabolic Profiling in Rat Plasma, Urine, and Bile}

The radiochromatograms of the urine samples collected for 0-6 and 6-24 $\mathrm{h}$ after oral administration showed the radioactivity peaks derived from at least seven different metabolites, R1-R4, R9-R10, R19, and YM758 (Fig. 2). MS analysis confirmed that each peak was derived from one metabolite. From the radiochromatogram of urine obtained at 0-6 h (Fig. 2a), the major metabolite was estimated to be R10, and it accounted for $23.0 \%$ (calculated from the peak area) of the urinary radioactivity. The unchanged drug was also detected, representing $15.6 \%$ of the urinary radioactivity. Relatively large peaks, representing R9, R4, R19, and R3, accounted for 7.2, 17.6, 14.4, and $13.1 \%$ of the urinary radioactivity, respectively. From the radiochromatogram of the urine sample obtained at 6-24 $\mathrm{h}$ after administration (Fig. 2b), the major metabolite was estimated to be R4; it accounted for $25.8 \%$ of the urinary radioactivity. The unchanged drug was also detected, representing $9.8 \%$ of the urinary radioactivity. Relatively large peaks, representing R10, R9, and R3, accounted for 9.7, 15.6, and $14.6 \%$ of the urinary radioactivity, respectively.

At least four different radioactivity peaks were observed on the radiochromatograms of the bile sample collected for 0-6 and 6-24 h after oral administration (Fig. 3), but the radioactivity peaks were presumed to contain several metabolites (RT $30.9 \mathrm{~min}, \mathrm{R} 14$ and R16; RT $33.5 \mathrm{~min}$, R17-R19; RT $44.4 \mathrm{~min}, \mathrm{R} 1$ and R2), except for the peak derived from $\mathrm{R} 10$. In the radiochromatogram of rat bile obtained at $0-6 \mathrm{~h}$ (Fig. 3a), the major metabolite was estimated to be R10, and it accounted for $37.0 \%$ of the biliary radioactivity. A peak representing the unchanged drug was not detected. The mixtures of R14 and R16, R17R19, and R1 and R2 accounted for 20.4, 25.4, and $17.2 \%$ of the biliary radioactivity, respectively. The main metabolite in the bile sample obtained for 6-24 h after
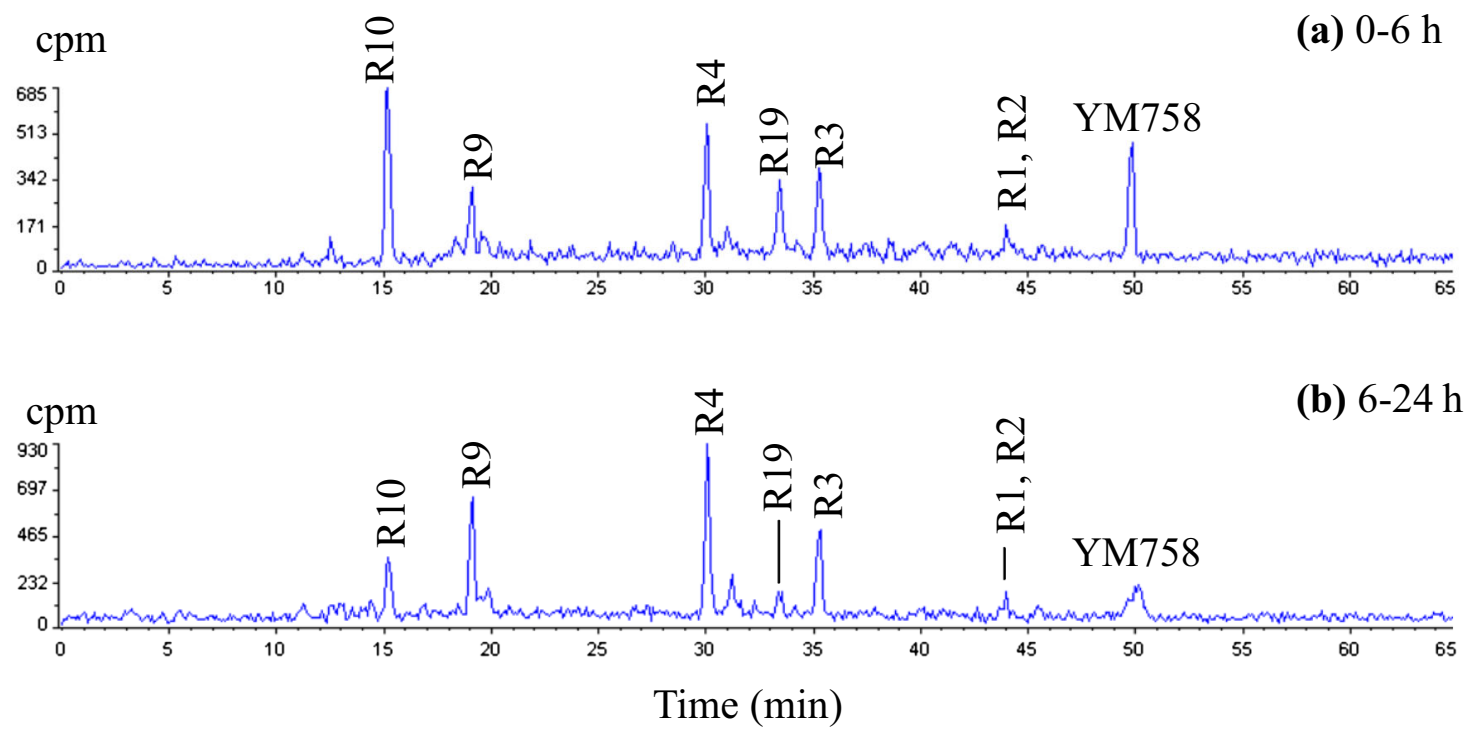

Fig. 2 Radiochromatograms of rat urine samples collected for $0-6 \mathrm{~h}(\mathbf{a})$ and $6-24 \mathrm{~h}(\mathbf{b})$ after oral administration of ${ }^{14} \mathrm{C}-\mathrm{YM} 758$ at $1 \mathrm{mg} / \mathrm{kg}$ 


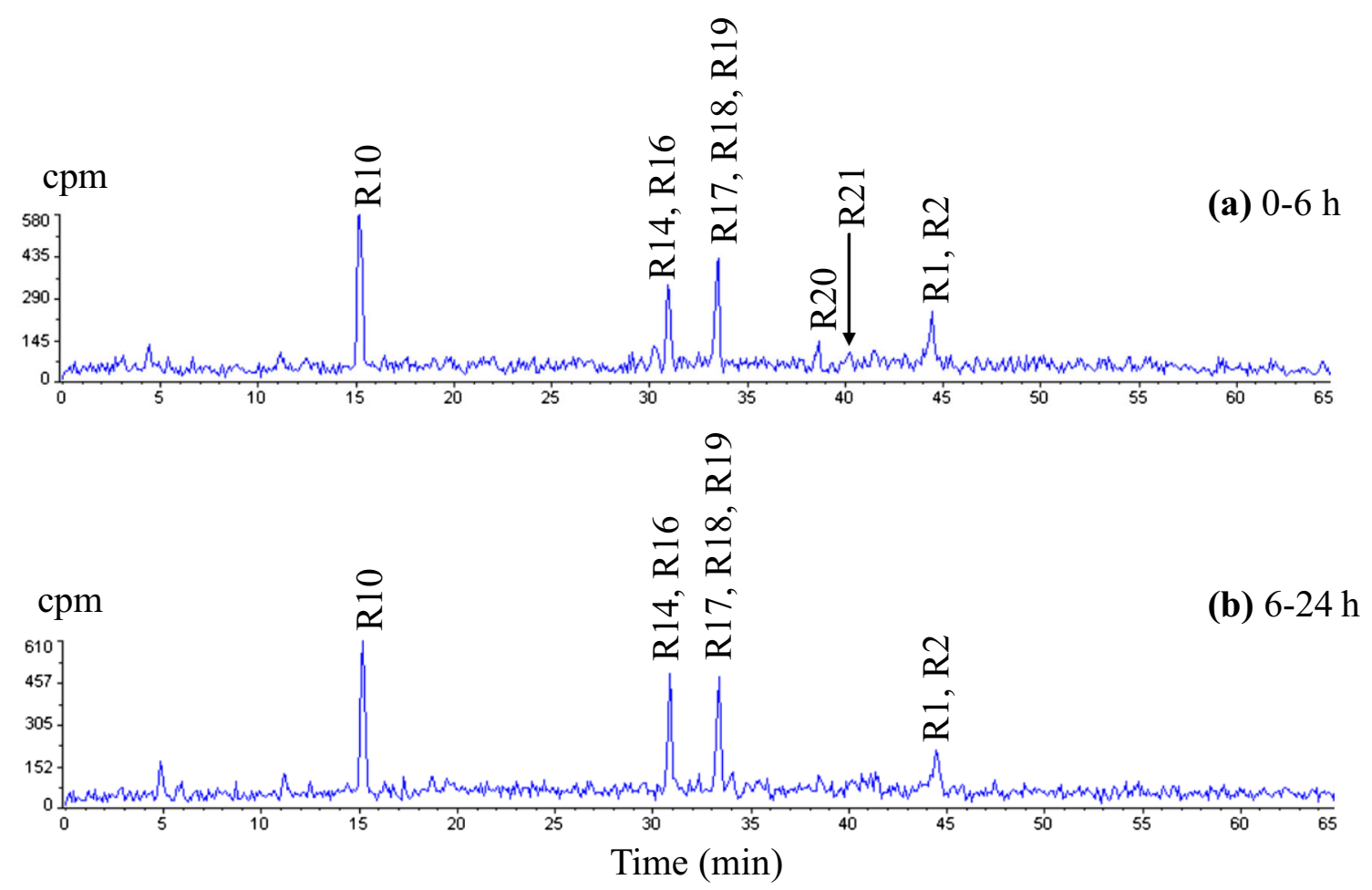

Fig. 3 Radiochromatograms of rat bile samples collected for $0-6 \mathrm{~h}(\mathbf{a})$ and $6-24 \mathrm{~h}(\mathbf{b})$ after oral administration of ${ }^{14} \mathrm{C}-\mathrm{YM} 758$ at $1 \mathrm{mg} / \mathrm{kg}$

dpm
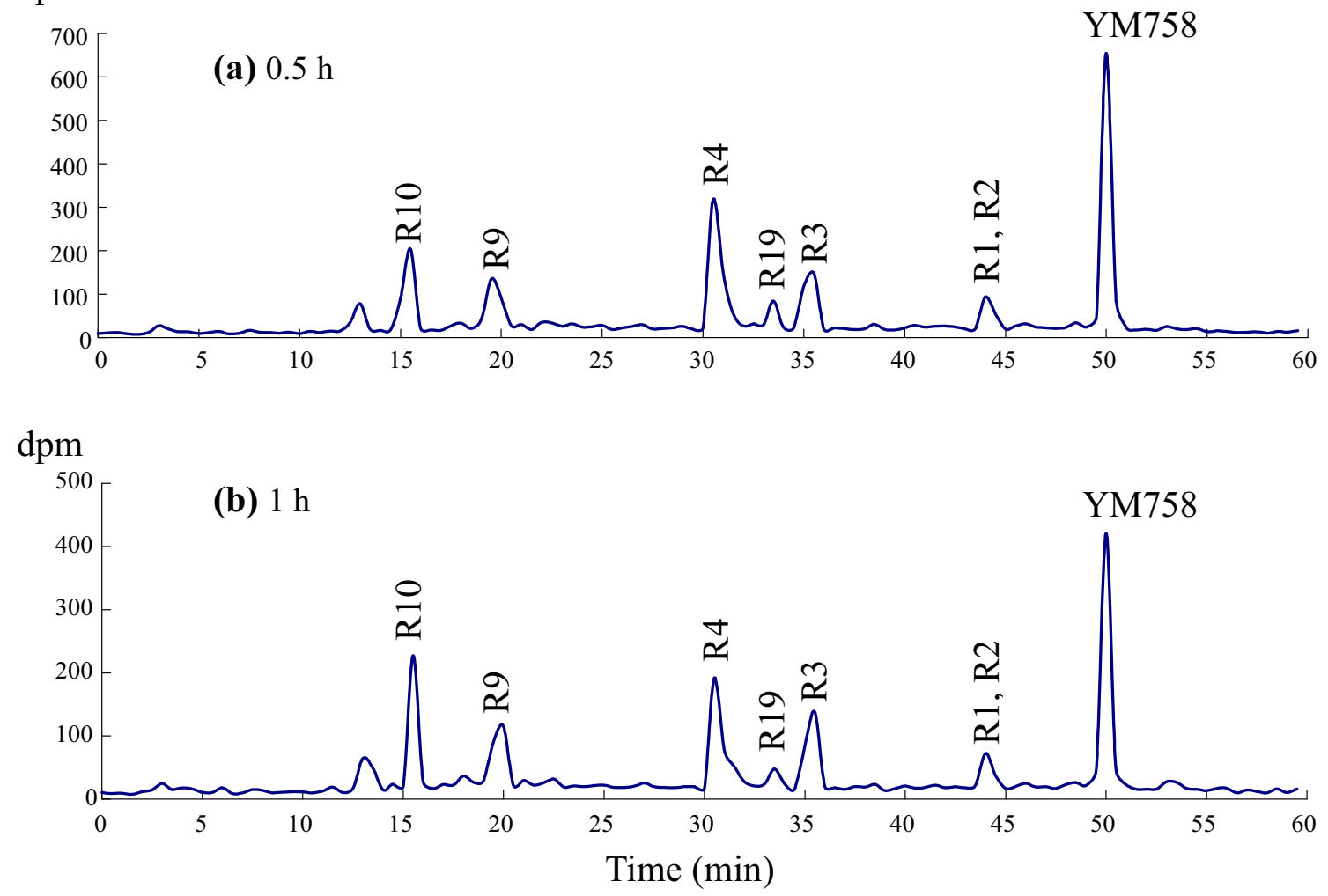

Fig. 4 Radiochromatograms of rat plasma samples collected at $0.5 \mathrm{~h}(\mathbf{a})$ and $1 \mathrm{~h}(\mathbf{b})$ after oral administration of ${ }^{14} \mathrm{C}-\mathrm{YM} 758$ at $1 \mathrm{mg} / \mathrm{kg}$ 
administration was also estimated to be R10 (Fig. 3b), and it accounted for $33.9 \%$ of the biliary radioactivity. The mixtures of R14 and R16, R17-R19, and R1 and R2 accounted for $24.4,22.5$, and $12.5 \%$ of biliary radioactivity, respectively.

The excretion rates and percentage of dose of the metabolites were calculated from the results described above and are shown in Table 3.

The radiochromatograms of plasma obtained at 0.5 and $1 \mathrm{~h}$ after oral administration showed several peaks derived from the metabolites and the unchanged drug (Fig. 4). These radiochromatograms of plasma at 0.5 and $1 \mathrm{~h}$ were very similar to those of urine collected during the $0-6 \mathrm{~h}$ period after dosing. Radioactivity peaks at RTs of 15.5 , $19.5,30.5,33.5,35.5,44.0$, and 50.0 min were estimated to be R10, R9, R4, R19, R3, the mixture of R1 and R2, and the unchanged drug, respectively. The major metabolites in rat plasma were estimated to be both R4 and R10.

\subsection{Identification of Metabolites of YM758 in Mouse, Rat, Rabbit, Dog, and Monkey Plasma}

On the SRM chromatograms, four metabolites, R3 (YM385459), R4 (YM-252124), R8 (YM-385461), and R16 (AS2036329), were detected in the plasma samples collected $2 \mathrm{~h}$ post-dose from mice, rats, rabbits, and dogs, and $0.5 \mathrm{~h}$ post-dose from monkeys (Fig. 5). Therefore, those metabolites were identified as circulating metabolites of YM758. The detected peaks in the plasma samples of other time points were not essentially different (data not shown).

\subsection{Structure Elucidation of Metabolites of YM758 in Rats}

The structures of YM758 and its metabolites were unambiguously assigned by the acquisition and rationalization of their ${ }^{1} \mathrm{H}$ and ${ }^{13} \mathrm{C}$-NMR signals (Table 1). Although we were not able to assign NMR chemical shifts of R9 to the estimated structure, its structure was elucidated according to the comparison of NMR spectra with the authentic sample (YM-234903). The molecular weight, mass shifts from the unchanged drug, and proposed chemical structures of the metabolites are listed in Table 2.

Both R1 and R2 were estimated to be 21-hydroxylated metabolites of YM758. Although they were isolated separately in the course of the metabolite isolation, their RTs were almost the same. Given the result of the NMR analysis, they were considered to represent diastereomers at the position of the hydroxyl group. The current study was unable to determine the stereochemical structures of R1 and R2. R3 was formed by elimination of the $\mathrm{N}$-ethyl(4fluorophenyl)carboxamide moiety and oxidation of the piperidine ring. R4 was estimated to be the oxidative elimination product of the $N$-ethyl(4-fluorophenyl)carboxamide moiety of YM758. R8 was 2-[(4-fluorophenyl)-carbonylamino] acetic acid. R9 was estimated to be (3R)-1-\{2[(4-fluorobenzoyl)amino]ethyl $\}$ piperidine-3-carboxylic acid. Both R10 and R11 were $O$ - $\beta$-glucuronides of demethylated R4. Both R16 and R17 were $O$ - $\beta$-glucuronides of demethylated YM758. R18 was a sulfate of $\mathrm{R} 1$ or R2. R19 was a ring-cleavage metabolite at positions 18-19 of YM758. R20 was a sulfate conjugate of 31-demethylated YM758. R21 was a sulfate conjugate of 29-demethylated YM758. Although R12, R13, and R14 were estimated to be glutathione conjugates and their sequential metabolites according to the molecular weights, we were unable to further elucidate the detail of the structures because of the limited amounts of the samples obtained.

\section{Discussion}

In this study, we conducted in vivo quantitative metabolic profiling of YM758 in rats using urine, bile, and plasma samples collected after oral administration of ${ }^{14} \mathrm{C}$-YM758 $1 \mathrm{mg} / \mathrm{kg}$. The main metabolite generated was R10 (22.14\% of dose, Table 3). In addition, other metabolite peaks, R1-R4, R9, R14, R16-R19, were detected in the urine and bile samples. These metabolites were generated via various metabolic pathways. Therefore, the metabolism of YM758 in rats is considered to be diverse. The metabolic profile in plasma at 0.5 and $1 \mathrm{~h}$ was similar to that in the urine, and the main circulating metabolites in rats were thought to be R4 and R10. Although R11 was isolated from the rat bile collected after a large dosage of YM758, and the structure was elucidated using NMR and MS, it was not detected in the radiochromatograms of rat plasma, urine, and bile samples.

The presence of the metabolites R3, R4, R8, and R16, which have already been found in human plasma [8], were also found in the plasma of mice, rats, rabbits, dogs, and monkeys after a single administration of YM758. These results suggest that there are no human-specific circulating metabolites. Consequently, we intend to conduct pharmacokinetic studies to confirm the exposure to the metabolites in the experimental animals.

After oral administration of a large quantity of YM758 to rats, bile and urine samples were collected for up to $24 \mathrm{~h}$. Metabolites R1-R4, R8, and R9 were isolated from the urine samples, and R10-R14 and R16-R21 were isolated from the bile samples via chromatographic separation. The chemical structures were elucidated with MS and NMR analyses. The postulated metabolic pathways are shown in Fig. 6. The main metabolic pathways of YM758 
Fig. 5 Selected reaction monitoring chromatograms of R3 (a), R4 (b), R8 (c), and R16 (d) in plasma samples collected from mice, rats, rabbits, dogs, and monkeys after a single dose of YM758, and authentic samples of those metabolites
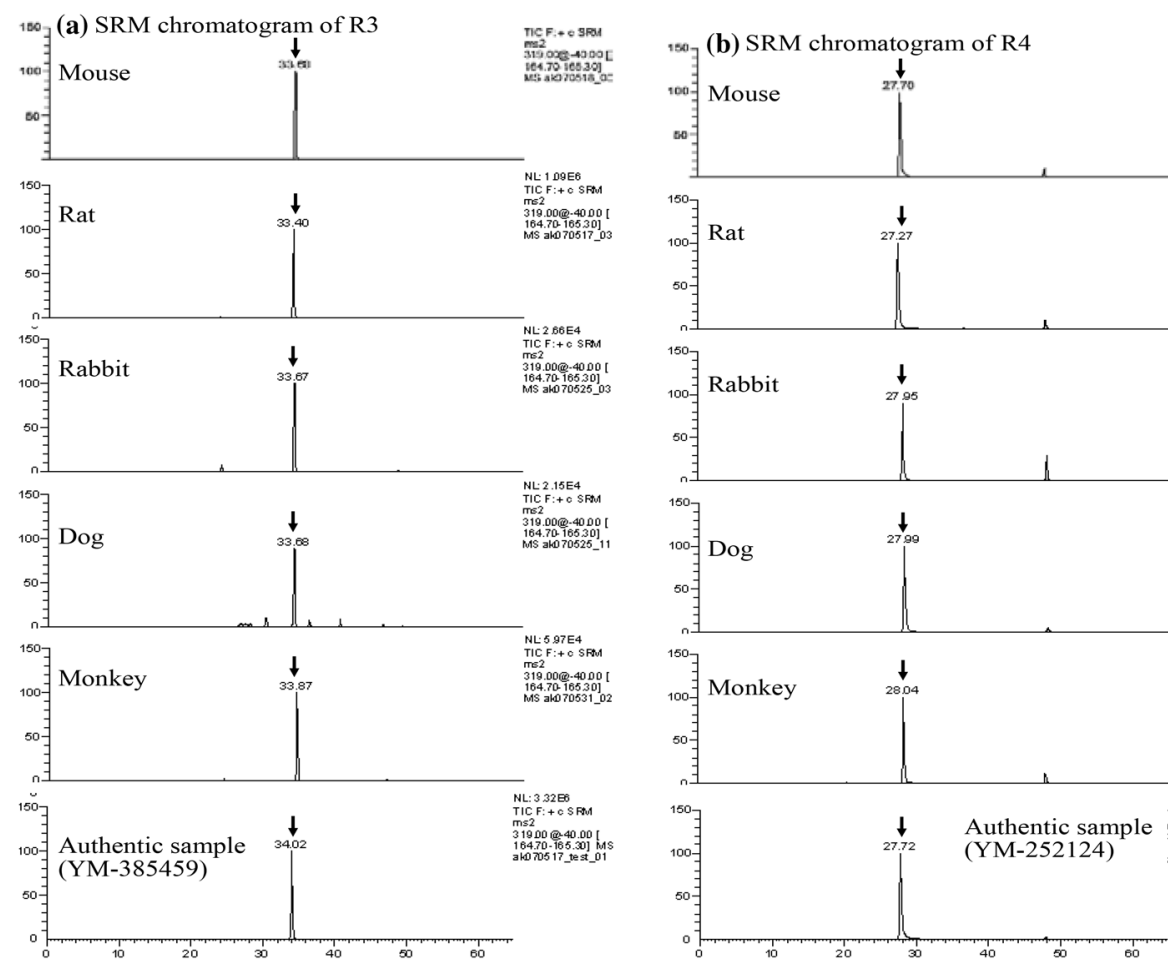

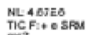

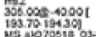

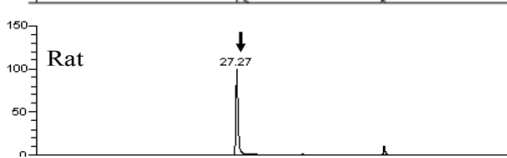

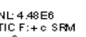

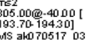

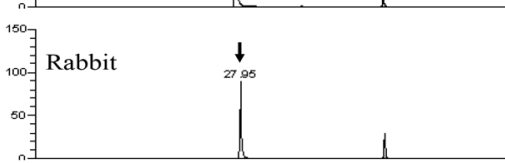

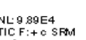

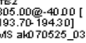
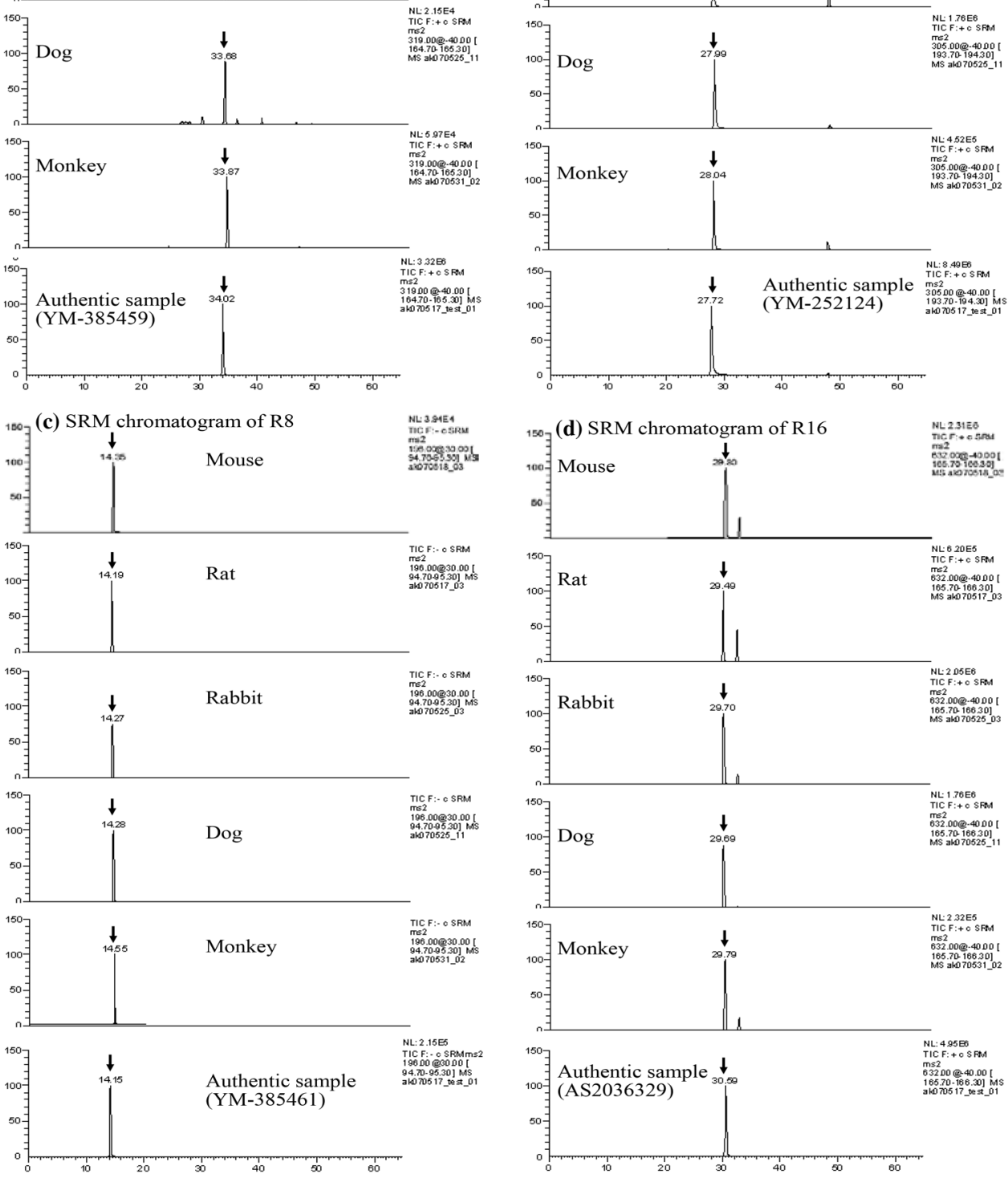
Table $1{ }^{1} \mathrm{H}$ and ${ }^{13} \mathrm{C}-\mathrm{NMR}$ assignment for YM758 monophosphate and its metabolites isolated from rat urine and bile samples

\begin{tabular}{|c|c|c|c|c|c|c|c|c|c|c|c|c|}
\hline \multirow[t]{2}{*}{ Position } & \multicolumn{2}{|c|}{ YM758 } & \multicolumn{2}{|l|}{$\mathrm{R} 1$} & \multicolumn{2}{|l|}{$\mathrm{R} 2$} & \multicolumn{2}{|l|}{$\mathrm{R} 3$} & \multicolumn{2}{|l|}{$\mathrm{R} 4$} & \multicolumn{2}{|l|}{$\mathrm{R} 8$} \\
\hline & $\delta_{\mathrm{H}}$ & $\delta_{\mathrm{C}}$ & $\delta_{\mathrm{H}}$ & $\delta_{\mathrm{C}}$ & $\delta_{\mathrm{H}}$ & $\delta_{\mathrm{C}}$ & $\delta_{\mathrm{H}}$ & $\delta_{\mathrm{C}}$ & $\delta_{\mathrm{H}}$ & $\delta_{\mathrm{C}}$ & $\delta_{\mathrm{H}}$ & $\delta_{\mathrm{C}}$ \\
\hline \multicolumn{13}{|c|}{ Basic structure of unchanged drug } \\
\hline 1 & - & 166.5 & - & ND & - & ND & - & - & - & - & - & 167.0 \\
\hline 2,6 & 7.20 & 116.5 & 7.20 & 116.4 & 7.21 & 116.5 & - & - & - & - & 7.19 & 116.0 \\
\hline 3,5 & 7.97 & 131.3 & 7.90 & 131.1 & 7.91 & 131.0 & - & - & - & - & 7.91 & 131.0 \\
\hline 4 & - & 131.4 & - & ND & - & ND & - & - & - & - & - & 132.0 \\
\hline 7 & - & 169.8 & - & ND & - & ND & - & - & - & - & - & 169.0 \\
\hline 9 & 3.80 & 36.0 & $\begin{array}{l}3.65 \\
3.70\end{array}$ & 36.8 & 3.60 & 37.0 & - & - & - & - & 4.05 & 43.0 \\
\hline 10 & 3.29 & 58.1 & 3.04 & 58.3 & 2.90 & ND & - & - & - & - & - & ND \\
\hline 12 & $\begin{array}{l}3.27 \\
3.31\end{array}$ & 54.2 & $\begin{array}{l}4.65 \\
4.75\end{array}$ & $\begin{array}{l}47.8 \\
48.1\end{array}$ & $\begin{array}{l}4.57 \\
4.64\end{array}$ & 48.0 & $\begin{array}{l}3.36 \\
3.46\end{array}$ & 44.5 & 3.23 & 47.0 & - & - \\
\hline 13 & 3.52 & 37.5 & 2.90 & ND & ND & ND & 3.27 & 37.0 & 3.27 & 36.5 & - & - \\
\hline 14 & $\begin{array}{l}1.72 \\
2.01\end{array}$ & 26.3 & $\begin{array}{l}1.72 \\
1.93\end{array}$ & 27.0 & $\begin{array}{l}1.77 \\
1.97\end{array}$ & ND & $\begin{array}{l}1.94 \\
1.98 \\
2.03\end{array}$ & 25.0 & $\begin{array}{l}1.72 \\
1.92\end{array}$ & 26.5 & - & - \\
\hline 15 & $\begin{array}{l}1.93 \\
2.06\end{array}$ & 22.7 & $\begin{array}{l}1.86 \\
1.91\end{array}$ & 23.5 & 1.85 & ND & 2.43 & 31.0 & 1.83 & 22.0 & - & - \\
\hline 16 & $\begin{array}{l}3.16 \\
3.42\end{array}$ & $\begin{array}{l}55.5 \\
55.6\end{array}$ & $\begin{array}{l}3.17 \\
3.31\end{array}$ & 54.7 & $\begin{array}{l}3.10 \\
3.18\end{array}$ & $\begin{array}{l}55.0 \\
56.0\end{array}$ & - & 174.5 & $\begin{array}{l}3.08 \\
3.18\end{array}$ & 45.0 & - & - \\
\hline 17 & - & 173.2 & - & ND & - & ND & - & 173.5 & - & 174.0 & - & - \\
\hline 18 & $\begin{array}{l}4.52 \\
4.62 \\
4.67 \\
4.72\end{array}$ & 48.2 & $\begin{array}{l}4.17 \\
5.11\end{array}$ & 45.0 & $\begin{array}{l}4.29 \\
4.96\end{array}$ & 45.0 & $\begin{array}{l}4.59 \\
4.63 \\
4.71\end{array}$ & 48.2 & $\begin{array}{l}4.56 \\
4.65 \\
4.64\end{array}$ & 48.0 & - & - \\
\hline 20 & $\begin{array}{l}3.78 \\
3.80 \\
3.71 \\
3.79\end{array}$ & 44.8 & $\begin{array}{l}3.61 \\
4.06\end{array}$ & 51.5 & $\begin{array}{l}3.66 \\
3.95\end{array}$ & 51.5 & $\begin{array}{l}3.78 \\
3.80\end{array}$ & $\begin{array}{l}42.0 \\
44.5\end{array}$ & $\begin{array}{l}3.74 \\
3.77\end{array}$ & $\begin{array}{l}44.5 \\
42.0\end{array}$ & - & - \\
\hline 21 & $\begin{array}{l}2.75 \\
2.87\end{array}$ & $\begin{array}{l}28.7 \\
30.1\end{array}$ & 4.70 & 67.0 & 4.70 & 67.0 & $\begin{array}{l}2.77 \\
2.87\end{array}$ & $\begin{array}{l}29.0 \\
30.0\end{array}$ & $\begin{array}{l}2.76 \\
2.86\end{array}$ & $\begin{array}{l}29.0 \\
30.0\end{array}$ & - & - \\
\hline 22 & - & $\begin{array}{l}127.6 \\
128.1\end{array}$ & - & ND & - & ND & - & $\begin{array}{l}127.0 \\
128.0\end{array}$ & - & 128.0 & - & - \\
\hline 23 & $\begin{array}{l}6.73 \\
6.74\end{array}$ & $\begin{array}{l}113.1 \\
113.2\end{array}$ & $\begin{array}{l}6.96 \\
7.01\end{array}$ & $\begin{array}{l}113.5 \\
112.7\end{array}$ & $\begin{array}{l}6.98 \\
7.01\end{array}$ & $\begin{array}{l}113.0 \\
112.5\end{array}$ & 6.75 & 113.0 & 6.74 & 113.0 & - & - \\
\hline 24 & - & $\begin{array}{l}149.4 \\
149.5\end{array}$ & - & ND & - & ND & - & 150.0 & - & 150.0 & - & - \\
\hline 25 & - & $\begin{array}{l}149.5 \\
149.7\end{array}$ & - & ND & - & ND & - & 150.0 & - & 150.0 & - & - \\
\hline 26 & $\begin{array}{l}6.71 \\
6.83\end{array}$ & 111.1 & $\begin{array}{l}6.74 \\
6.80\end{array}$ & $\begin{array}{l}110.2 \\
110.1\end{array}$ & $\begin{array}{l}6.75 \\
6.80\end{array}$ & $\begin{array}{l}110.1 \\
110.0\end{array}$ & 6.75 & 111.0 & $\begin{array}{l}6.73 \\
6.79\end{array}$ & 111.0 & - & - \\
\hline 27 & - & $\begin{array}{l}126.0 \\
126.1\end{array}$ & - & ND & - & ND & - & $\begin{array}{l}126.0 \\
127.0\end{array}$ & - & 126.0 & - & - \\
\hline 29 & 3.79 & 56.6 & 3.82 & 56.6 & 3.81 & 56.5 & 3.80 & 56.5 & 3.79 & 56.5 & - & - \\
\hline 31 & 3.79 & 56.6 & 3.83 & 56.6 & 3.82 & 56.5 & 3.80 & 56.5 & 3.79 & 56.5 & - & - \\
\hline
\end{tabular}


Table 1 continued

\begin{tabular}{|c|c|c|c|c|c|c|c|c|c|c|c|}
\hline \multirow[t]{2}{*}{ Position } & \multirow{2}{*}{$\begin{array}{l}\mathrm{R} 10 \\
\delta_{\mathrm{H}}\end{array}$} & \multirow{2}{*}{$\begin{array}{l}\mathrm{R} 11 \\
\delta_{\mathrm{H}}\end{array}$} & \multicolumn{2}{|l|}{ R16 } & \multicolumn{2}{|l|}{$\mathrm{R} 17$} & \multirow{2}{*}{$\begin{array}{l}\mathrm{R} 18 \\
\delta_{\mathrm{H}}\end{array}$} & \multicolumn{2}{|l|}{ R19 } & \multirow{2}{*}{$\begin{array}{l}\mathrm{R} 20 \\
\delta_{\mathrm{H}}\end{array}$} & \multirow{2}{*}{$\begin{array}{l}\mathrm{R} 21 \\
\delta_{\mathrm{H}}\end{array}$} \\
\hline & & & $\delta_{\mathrm{H}}$ & $\delta_{\mathrm{C}}$ & $\delta_{\mathrm{H}}$ & $\delta_{\mathrm{C}}$ & & $\delta_{\mathrm{H}}$ & $\delta_{\mathrm{C}}$ & & \\
\hline \multicolumn{12}{|c|}{ Basic structure of unchanged drug } \\
\hline 1 & - & - & - & ND & - & ND & - & - & 164.0 & - & - \\
\hline 2,6 & - & - & 7.19 & 116.0 & 7.15 & 116.0 & 7.23 & 7.27 & 115.7 & 7.22 & 7.22 \\
\hline 3,5 & - & - & 7.89 & 131.0 & 7.89 & 131.0 & 7.90 & 7.95 & 130.5 & 7.94 & 7.91 \\
\hline 4 & - & - & - & ND & - & ND & - & - & 131.9 & - & - \\
\hline 7 & - & - & - & ND & - & ND & - & - & 165.0 & - & - \\
\hline \multirow[t]{2}{*}{9} & - & - & 3.61 & 37.0 & 3.74 & 36.0 & 3.67 & 3.34 & 37.7 & ND & ND \\
\hline & & & 3.68 & & & & & & & & \\
\hline \multirow[t]{2}{*}{10} & - & - & 2.91 & 58.0 & 3.30 & ND & $3.0-3.4$ & 2.40 & 57.8 & ND & ND \\
\hline & & & & & & & & 2.45 & & & \\
\hline \multirow[t]{2}{*}{12} & 3.11 & 3.10 & 2.58 & 57.0 & 3.36 & 58.0 & $3.0-3.7$ & 2.00 & 56.6 & ND & ND \\
\hline & 3.19 & 3.24 & 3.15 & & & & & 2.76 & & & \\
\hline 13 & 3.24 & 3.15 & 3.15 & 39.0 & 3.10 & ND & ND & 2.20 & 43.0 & ND & ND \\
\hline \multirow[t]{2}{*}{14} & 1.72 & 1.75 & 1.61 & ND & 1.72 & 26.0 & 1.85 or 1.94 & 1.30 & 27.6 & ND & ND \\
\hline & 1.97 & 1.92 & 1.81 & & 1.93 & & & 1.59 & & & \\
\hline \multirow[t]{2}{*}{15} & 1.82 & 1.86 & 1.81 & ND & 1.93 & 23.0 & & 1.37 & 24.9 & ND & ND \\
\hline & 1.88 & & & & & & & 1.55 & & & \\
\hline \multirow[t]{3}{*}{16} & 3.02 & 3.04 & 2.58 & 57.0 & 3.36 & 58.0 & $3.0-3.7$ & 1.93 & 54.0 & ND & ND \\
\hline & 3.11 & 3.10 & 3.15 & & & & & 2.69 & & & \\
\hline & 3.25 & 3.16 & & & & & & & & & \\
\hline 17 & - & - & - & ND & - & ND & - & - & 181.5 & - & - \\
\hline \multirow[t]{2}{*}{18} & 4.51 & 4.55 & 4.59 & 45.5 & 4.47 & 45.0 & 4.72 & - & 173.8 & 4.49 & 4.60 \\
\hline & 4.57 & & 4.68 & 48.0 & 4.59 & 48.0 & & & & 4.67 & \\
\hline \multirow[t]{3}{*}{20} & 3.63 & 3.65 & 3.72 & 42.0 & 3.55 & 42.0 & 3.63 & 3.24 & 42.1 & 3.70 & ND \\
\hline & 3.71 & 3.78 & 3.73 & 45.0 & 3.82 & & 4.02 & & & 3.74 & \\
\hline & 3.80 & & & & & & & & & & \\
\hline \multirow[t]{2}{*}{21} & 2.78 & 2.76 & 2.73 & 29.0 & 2.78 & 28.0 & ND & 3.00 & 32.8 & 2.73 & ND \\
\hline & 2.85 & 2.81 & 2.83 & & & & & & & 2.81 & \\
\hline 22 & - & - & - & ND & - & ND & - & - & ND & - & - \\
\hline 23 & 6.79 & 7.00 & 7.01 & 118.0 & 6.74 & 114.0 & 7.03 & 6.71 & 114.1 & 7.21 & 6.81 \\
\hline & 6.80 & 7.02 & 7.03 & & 6.78 & & 7.09 & & & & \\
\hline 24 & - & - & - & ND & - & ND & - & - & 150.0 & - & - \\
\hline 25 & - & - & - & ND & - & ND & - & - & 146.8 & - & - \\
\hline 26 & 7.02 & 6.78 & 6.76 & 112.0 & 6.94 & 115.0 & 7.29 & 7.27 & 114.1 & 6.74 & 7.28 \\
\hline & 7.04 & 6.81 & 6.83 & & 7.05 & & 7.32 & & & & \\
\hline 27 & - & - & - & ND & - & ND & - & - & 130.0 & - & - \\
\hline 29 & - & 3.83 & 3.82 & 57.0 & - & - & - & 3.71 & 56.0 & 3.78 & - \\
\hline 31 & 3.82 & - & - & - & 3.80 & 57.0 & 3.84 & 3.75 & 56.0 & - & 3.80 \\
\hline & 3.83 & & & & & & & & & & \\
\hline Glucuronic ac & & & & & & & & & & & \\
\hline $1^{\prime}$ & 4.93 & 4.92 & 4.84 & 103.0 & 4.99 & 103.0 & - & - & - & - & - \\
\hline $2^{\prime}, 3^{\prime}, 4^{\prime}, 5^{\prime}$ & 3.51 & & 3.50 & 74.0 & 3.55 & 75.0 & - & - & - & - & - \\
\hline & 3.54 & 3.52 & 3.50 & 78.0 & 3.55 & 75.0 & & & & & \\
\hline & 3.80 & 3.73 & 3.50 & 77.0 & 3.55 & 77.0 & & & & & \\
\hline & & & 3.70 & & 3.74 & 77.0 & & & & & \\
\hline $6^{\prime}$ & - & - & - & ND & - & ND & - & - & - & - & - \\
\hline
\end{tabular}

'-' indicates not applicable, $N D$ not detected 
Table 2 Nominal mass, mass shifts from YM758 and proposed chemical structures

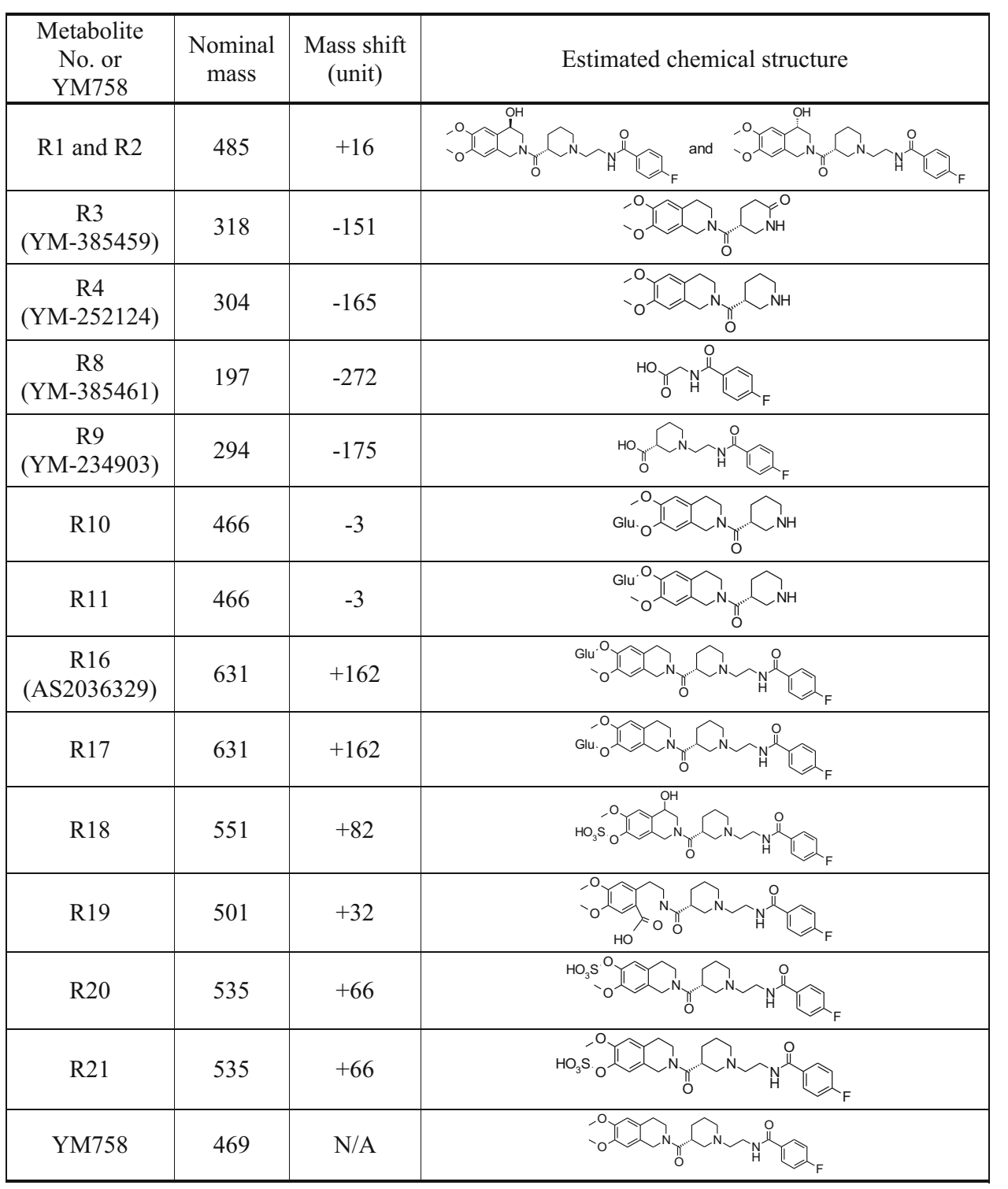

Glu glucuronic acid, NA not applicable

\begin{tabular}{lll}
\hline Metabolite number/YM758 & \multicolumn{2}{l}{ Excretion rates of metabolites (\% of dose) } \\
\cline { 2 - 3 } & $\begin{array}{l}\text { Urine } \\
0-24 \mathrm{~h}\end{array}$ & Bile \\
& $\mathrm{NC}$ & $0-24 \mathrm{~h}$ \\
\hline Mixture of R1 and R2 & 1.39 & 9.07 \\
R3 & 1.98 & $\mathrm{NC}$ \\
R4 & 0.90 & $\mathrm{NC}$ \\
R9 & 2.15 & $\mathrm{NC}$ \\
R10 & $\mathrm{NC}$ & 19.99 \\
Mixture of R14 and R16 & $\mathrm{NA}$ & 11.41 \\
Mixture of R17, R18, and R19 & 1.24 & 13.67 \\
Sole R19 & 1.52 & $\mathrm{NA}$ \\
YM758 & NC \\
\hline
\end{tabular}

$N A$ not applicable, $N C$ not calculated because of the trace amount or undetectable metabolite
Table 3 Excretion rate of YM758 and its metabolites in rat urine and bile 


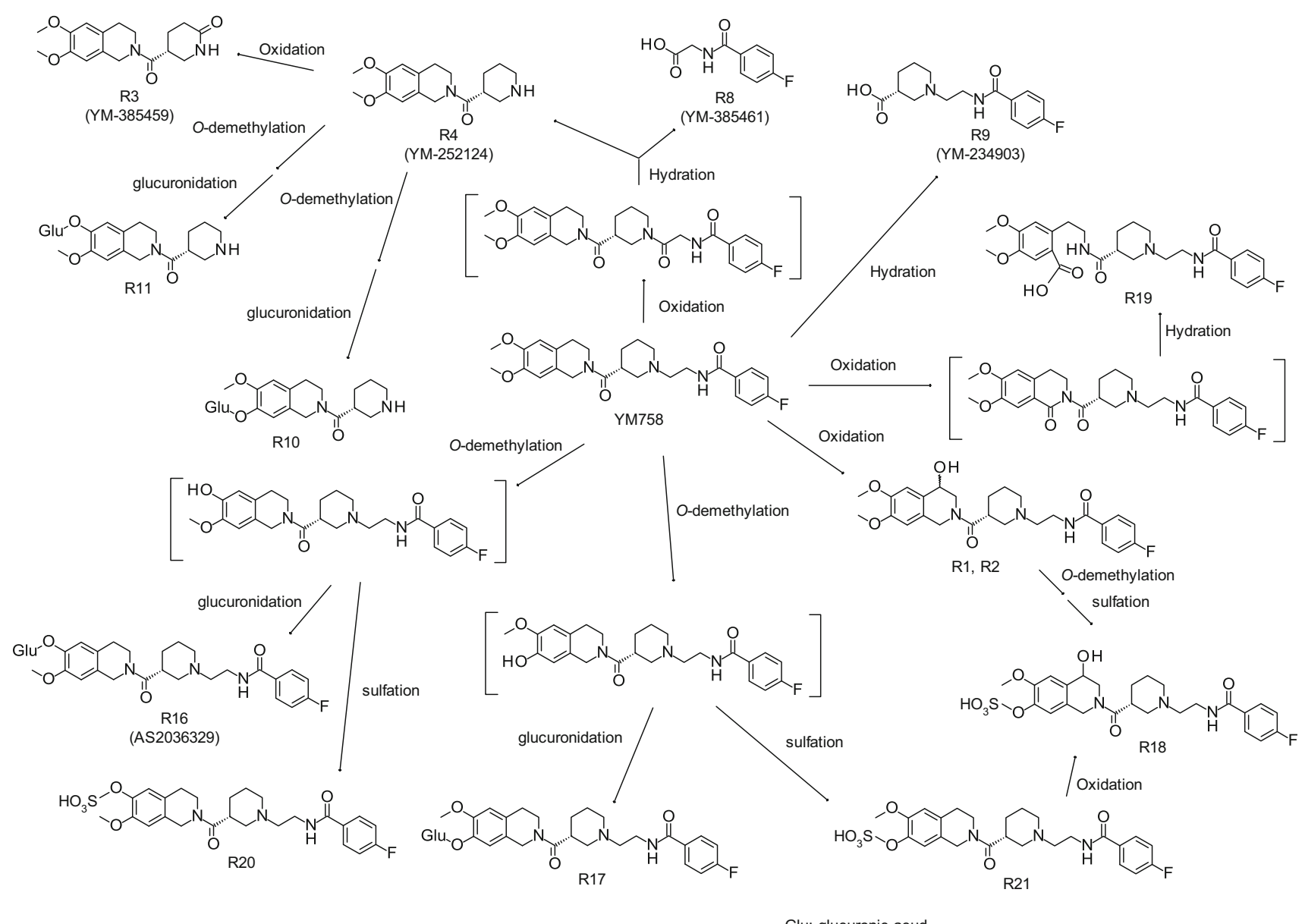

Fig. 6 Postulated metabolic pathways of YM758

in rats are thought to be (1) hydroxylation (R1, R2, and R18); (2) oxidation followed by hydration (R3, R4, R8, and R19); (3) amide hydrolysis (R9); (4) $O$-demethylation followed by sulfate or glucuronide conjugation (R10, R11, R16-R18, R20, and R21).

Acknowledgments The author thanks Mr. Aiji Miyashita, Mr. Kinya Soda, Ms Yoko Susaki, Ms. Takako Yokoi, Mr. Katsuhiro Suzuki, Dr. Kazuyoshi Nozaki, Dr. Akio Kawamura, Dr. Takafumi Iwatsubo, Dr. Takashi Usui, and Dr. Hidetaka Kamimura (Astellas Pharma Inc.) for their useful advice.

\section{Compliance with Ethical Standards}

Conflict of interest Naoyuki Nakada is an employee of Astellas Pharma Inc.

Funding No funding was received for the conduct of this study.

Open Access This article is distributed under the terms of the Creative Commons Attribution-NonCommercial 4.0 International License (http://creativecommons.org/licenses/by-nc/4.0/), which permits any noncommercial use, distribution, and reproduction in any medium, provided you give appropriate credit to the original author(s) and the source, provide a link to the Creative Commons license, and indicate if changes were made.

\section{References}

1. Yoshida S, Marumo K, Takeguchi K, Takahashi T, Mase $\mathrm{T}$. Development of a practical and scalable synthetic route to YM758 monophosphate, a novel if channel inhibitor. Org Process Res Dev. 2014;18:1721-27.

2. Buckberg GD, Fixler DE, Archie JP, Hoffman JI. Experimental subendocardial ischemia in dogs with normal coronary arteries. Circ Res. 1972;30:67-81.

3. Indolfi C, Guth BD, Miura T, Miyazaki S, Schulz R, et al. Mechanisms of improved ischemic regional dysfunction by bradycardia: studies on UL-FS 49 in swine. Circulation. 1989;80:983-93.

4. Opie L. Trial alert. Cardiovasc Drugs Ther. 1989;3:795-6.

5. Bucchi A, Barbuti A, Baruscotti M, DiFrancesco D. Heart rate reduction via selective 'funny' channel blockers. Curr Opin Pharmacol. 2007;7:208-13.

6. Umehara KI, Nakamata T, Suzuki K, Noguchi K, Usui T, et al. Pharmacokinetics of YK754, a novel If channel inhibitor in rats, dogs and humans. Eur J Drug Metab Pharmacokinet. 2008:33:117-27. 
7. Umehara KI, Seya K, Sonoda T, Nakamura E, Noguchi K, et al. Comparative evaluation of absorption, distribution, and excretion of YM758, a novel If channel inhibitor, between albino and nonalbino rats. Xenobiotica. 2008;38:527-39.

8. Umehara K, Shirai N, Iwatsubo T, Noguchi K, Usui $T$, et al. Identification of human metabolites of (-)- $N-\{2-[(\mathrm{R})-3-(6,7-$ dimethoxy-1,2,3,4-tetrahydroisoquinoline-2-carbonyl)piperidi no]ethyl \}-4-fluorobenzamide (YM758), a novel If channel inhibitor, and investigation of the transporter-mediated renal and hepatic excretion of these metabolites. Drug Metab Dispos. 2009;37:1646-57 